\title{
ВЛИЯНИЕ НЕБЛАГОПРИЯТНЫХ ЭКОЛОГИЧЕСКИХ ФАКТОРОВ НА АДАПТАЦИОННЫЕ ИЗМЕНЕНИЯ В ОРГАНИЗМЕ СПОРТСМЕНОВ
}

\section{IMPACT OF THE ADVERSE ENVIRONMENTAL FACTORS ON ATHLETES' ADAPTATION CHANGES}

\section{N. Zakharov \\ S. Shlapakova \\ I. Kondrashova \\ N. Kondykova}

Summary. The paper studies the peculiarities of athletes' adaptation changes under the impact of the adverse environmental factors. The obtained data allow us to evaluate the level of adaptability of the main functional systems of athletes from areas with the favourable environmental situation to the impact of regular physical activities, which is expressed by a high content of the muscular component of body weight, progressive indices of the state of the cardiovascular system, the index of adaptive capacity and functional tests. At the same time, the organism of athletes who live in conditions of environmental disadvantage is characterized by the presence of tendencies to develop stress mechanisms of adaptation of the cardiovascular system, as well as reliably lower results of functional tests. Sporting activities form a structural trace of adaptation changes, but their severity and level of manifestation in contaminated areas, however, are lower than in conditionally clean ones.

Keywords: environmental factors, adaptation, functional systems, morphology, human body, athletes.

\section{Актуальность исслеАования}

B процессе тренировок и соревнований организм спортсмена подвергается многим внешним воздействиям, важнейшим из которых являются физические нагрузки. В организме развиваются разнообразные адаптационные морфофункциональные
Захаров Никита Евгеньевич

К.б.н., доцент, ФГБОУ ВО «Брянский государственный инженерно-технологический университет» zaxarov1602@yandex.ru

Шлапакова Светлана Николаевна К.б.н., дочент, ФГБОУ ВО «Брянский государственный инженерно-технологический университет» shla-svetlana@yandex.ru Кондрашова Ирина Николаевна К.п.н., дочент, ФГБОУ ВО «Орловский государственный университет имени И.С. Тургенева» eco-kondrashova@yandex.ru

Кондыкова Наталия Николаевна

К.С.-Х.н., доцент, ФГБОУ ВО «Орловский государственный университет имени И.С. Тургенева» nkondykova@yandex.ru

Аннотация. Проведены исследования особенностей адаптационных изменений в организме спортсменов под влиянием неблагоприятных экологических факторов. Полученные данные позволяют высоко оценить уровень адаптированности основных функциональных систем организма спортсменов из районов с благоприятной экологической обстановкой к воздействию регулярных физических нагрузок, что выражается высоким содержанием мышечного компонента массы тела, прогрессивными показателями состояния сердечно-сосудистой системы, индекса адаптационного потенциала, функциональных проб. Вместе с тем организм спортсменов, проживающих в условиях экологического неблагополучия, характеризуется наличием тенденций к развитию напряжения механизмов адаптации сердечно-сосудистой системы, а также достоверно более низкими результатами функциональных проб. Занятия спортом формируют структурный след адаптационных изменений, однако его выраженность и уровень проявления в загрязненных районах оказываются ниже, чем в условно чистых.

Ключевые слова: экологические факторы, адаптация, функциональные системы, морфология, организм человека, спортсмены.

перестройки, обусловленные спецификой конкретного вида спортивной деятельности и проявляющиеся как в условиях относительного покоя, так и в процессе выполнения нагрузок. Адаптация к ним - приведение строения и функций организма в соответствие с потребностями спортивной деятельности. Результатом адаптации является способность организма нормаль- 
но функционировать в новых для него условиях при сохранении гомеостаза и высокой работоспособности $[1,7]$.

Долговременная адаптация, являясь следствием существенных структурных перестроек в органах и тканях, играет ведущую роль в развитии двигательных качеств, характеризуясь увеличением мощности физиологических систем и высоким уровнем функционирования систем жизнеобеспечения организма. Среди значительного числа показателей адаптации организма человека к разнообразным условиям окружающей среды, в том числе спортивным нагрузкам, наибольший интерес представляют морфофункциональные особенности организма спортсмена. Они оказывают влияние на проявление физических качеств, работоспособность и адаптацию организма к различным условиям внешней среды, на скорость восстановительных процессов $[5,6]$.

Функционирование человеческого организма в значительной мере обеспечивается взаимоотношениями с факторами окружающей среды. Особое место занимает проблема занятий физкультурой и спортом в экологически неблагополучных районах. Помимо высоких физических нагрузок спортсмены подвергаются воздействиям различных факторов среды, которые усиливают нагрузку на все физиологические системы организма человека. Изменение экологической обстановки, связанное с загрязнением окружающей среды, оказывает отрицательное влияние на здоровье и уровень физической подготовленности лиц, проживающих в районах экологического неблагополучия. Занятия физической культурой и спортом в неблагоприятных экологических условиях часто не дают ожидаемого оздоровительного эффекта, а в некоторых случаях отрицательно сказываются на состоянии здоровья занимающихся $[1,5]$. В литературе приводятся данные об отрицательном влиянии повышенных физических нагрузок на организм человека в экологически неблагоприятных условиях, особенно у детей и подростков в критические этапы онтогенеза [7]. В то же время имеются данные, свидетельствующие о том, что систематическая мышечная деятельность, спортивная тренировка приводят к повышению индивидуальных возможностей адаптации не только к определенному фактору среды, но и повышению физиологической устойчивости организма к воздействию сопутствующих факторов. В многочисленных исследованиях отмечено благотворное влияние физических тренировок на организм человека, многие авторы утверждают, что такие занятия повышают уровень функционального состояния и неспецифическую резистентность организма, что можно рассматривать как предпосылку высокой физической работоспособности и потенциальную способность организма эффектив- но приспосабливаться к условиям окружающей среды $[3,5]$.

Таким образом, оценка влияния неблагоприятных экологических факторов на уровень адаптационных изменений в организме спортсменов представляет на современном этапе актуальную задачу, обусловленную необходимостью изучения двигательной активности как фактора, влияющего на здоровье человека в экологически неблагоприятных условиях.

Целью работы являлось изучение влияния неблагоприятных экологических факторов на показатели адаптационных изменений в организме спортсменов, возникающих на фоне долговременных тренировочных нагрузок.

Задачами работы являлись изучение особенностей морфологических изменений в организме спортсменов в зависимости от уровня воздействия экологических факторов, исследование показателей кардиореспираторной системы организма спортсменов и оценка ее адаптированности к физическим нагрузкам в экологически различных условиях, оценка особенностей влияния экологических факторов среды обитания на характер и выраженность адаптационных изменений в организме лиц, регулярно занимающихся спортом.

Нами были использованы следующие методы:

- определение компонентов массы тела (жирового компонента, мышечной массы тела и костного компонента). Необходимые показатели массы тела, длины тела, толщины жировых складок и иных антропометрических показателей определялись по общепринятым методикам.

- методы оценки состояния кардиореспираторной системы организма человека (пульсометрия, тонометрия, спирометрия, функциональные пробы - проба Руфье, характеризующая переносимость динамической нагрузки, а также пробы на задержку дыхания (пробы Штанге и Генчи). На основании полученных данных рассчитывались показатели ударного и минутного объема крови, пульсового и среднего артериального давления, индекса адаптационного потенциала сердечно-сосудистой системы [2], показателя сердечной деятельности, являющегося критерием оптимальности вегетативного обеспечения сердечно-сосудистой системы при выполнении физической нагрузки. Данные, полученные в результате исследований, обрабатывали статистически.

Исследования проводились на базе спортивных школ олимпийского резерва юго-западных районов 
Брянской области (Новозыбковский, Красногорский, Злынковский), характеризующихся высоким уровнем техногенного радиационно-химического загрязнения среды обитания [4]. Кроме того, в целях сравнительной оценки влияния экологических факторов на адаптационные процессы в организме спортсменов были обследованы лица, проживающие в экологически условно чистых районах (г.Брянск, Жуковский район). Всего было обследовано 58 юношей (20-21 год), занимающихся циклическими видами спорта (легкая атлетика, лыжные гонки, плавание), имеющих стаж тренировок не менее 6-7 лет и спортивные разряды в избранных видах спорта. Все обследованные были разделены на две группы, согласно района проживания. В первую группу вошли спортсмены (32 человека) из экологически неблагополучных районов (І ЭГ), во вторую - представители условно чистых районов (26 человек) (II ЭГ). В каждой из групп нами проводились исследования особенностей адаптационных изменений организма спортсменов по описанным методикам.

\section{Результаты исслеАований и их обсужАение}

Известно, что лабильные компоненты массы тела мышечная и жировая ткани, являются объективными маркерами адаптивной реакции организма. Результаты исследований состава массы тела спортсменов из экологически различных районов, проведенных с целью дифференцировки ее отдельных компонентов, позволили установить, что мышечная масса спортсменов из экологически неблагополучных районов (І ЭГ) составляет $46,9 \pm 2,22 \%$ от массы тела, представителей

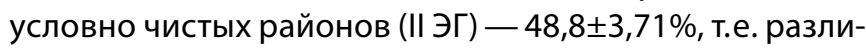
чия не превышают 4\%. Несколько более выраженными оказались различия в показателях содержания костной массы спортсменов из обследованных районов. Так, содержание костной массы у представителей I ЭГ состави-

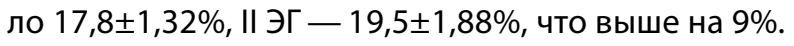

Наибольшие различия между спортсменами различных экологических групп обнаружены в показателях содержания жировой массы. Значительно более высоким содержанием жирового компонента в составе массы тела обладают представители условно чистых районов $(15,4 \pm 1,19 \%)$, что достоверно $(p \leq 0,01)$ превышает аналогичный показатель лиц, проживающих в районах экологического неблагополучия (9,8土0,94\%).

Большое значение для характеристики телосложения спортсменов имеет количественная оценка изучаемых признаков. Такой оценкой может являться состав тела человека, под которым понимается количественное соотношение метаболически активных (мышцы, кости, внутренние органы, нервная система) и мало- активных тканей (подкожные и внутренние жировые отложения). Изучение состава тела спортсменов позволяет более полно характеризовать и оценивать режим их деятельности, а также динамику восстановительных процессов.

Полученные нами результаты в целом согласуются с данными литературы о компонентах веса тела, где отмечается, что среднее содержание мышечной массы от веса тела у мужчин составляет $43 \%$, на долю костной ткани приходится в среднем $18 \%$, жировой - $12 \%$. По сравнению со средними величинами, содержание мышечной массы спортсменов несколько выше, чем у нетренированных мужчин [6]. Выраженных различий в содержании костной и мышечной массы тела спортсменов из экологически различных районов не выявлено. Достоверные различия отмечены в показателях содержания жировой массы, которая оказывается выше у представителей экологически чистого района. Полученные различия могут быть объяснены особенностями адаптации организма спортсменов к физическим нагрузкам различной направленности. Жировая ткань является важнейшим энергетическим депо организма, где протекают процессы образования нейтрального жира, его депонирование и расщепление с последующим использованием в биоэнергетике организма.

Результаты исследований состояния сердечно-сосудистой системы спортсменов из экологически различных районов позволили установить, что частота сердечных сокращений спортсменов из загрязненных районов (72,3 4,11 уд/мин) превышает аналогичный показатель лиц из экологически условно чистых районов $(61,7 \pm 3,79$ уд/мин) на $17,2 \%$.

Нами отмечена тенденция к развитию у спортсменов из условно чистых районов спортивной брадикардии, облегчающей восстановление сердечной мышцы и поддерживающей высокий уровень ее работоспособности, что является результатом изменения лабильности синусного узла и становления более совершенных форм нейрогуморальной регуляции сердца. При этом показатели частоты сердечных сокращений у представителей обеих экологических групп находятся в пределах возрастной нормы.

При анализе результатов исследований артериального давления существенных различий между представителями различных экологических групп выявлено не было.

В адаптации сердечной деятельности к мышечным нагрузкам принимает участие и другой показатель гемодинамики - ударный (систолический) объём крови. У представителей II ЭГ (условно чистые районы) выяв- 
лены более высокие значения ударного объема крови по сравнению со спортсменами І ЭГ $(72,7 \pm 2,52$ мл и 67,5 $\pm 4,92$ мл соответственно). Минутный объем кро-

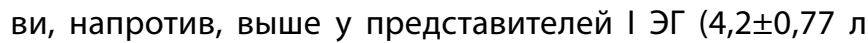

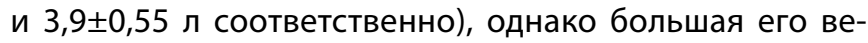
личина может объясняться не более высокой степенью адаптации сердечно-сосудистой системы, а более высоким уровнем частоты сердечных сокращений.

Индекс адаптационного потенциала (АП) обследованных спортсменов позволяет оценить адаптацию и функциональное состояние их системы кровообращения как удовлетворительные. У представителей чистых районов отмечаются более прогрессивные показатели индекса адаптационного потенциала. Удовлетворительной можно считать адаптацию, если индекс АП не превышает 2,6 балла. У спортсменов I ЭГ и II ЭГ индекс АП ниже данного значения на 17,65\% и 21,5\% соответственно. При этом у представителей I ЭГ индекс

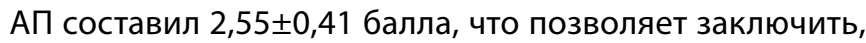
что сердечно-сосудистая система находится на грани нормы и напряжения механизмов адаптации.

Снижение адаптационного потенциала сопровождается некоторым смещением показателей миокардиально-гемодинамического гомеостаза в пределах нормальных значений, возрастает напряжение регуляторных систем, увеличивается «плата за адаптацию».

Периодический контроль за показателем сердечной деятельности (ПСД) является информативным критерием оценки адаптационного потенциала сердечно-сосудистой системы. При оценке результатов пробы Руфье выявлены достоверные различия $(p \leq 0,01)$ между представителями I ЭГ и II ЭГ. Значения ПСД спортсменов из экологически чистых районов $(4,88 \pm 0,81$ балла) позволяют оценить переносимость динамической нагрузки как отличную, из загрязненных - как хорошую

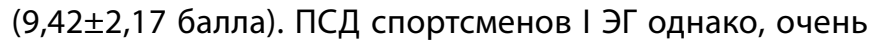
близок к удовлетворительному показателю.

Результаты исследований адаптационных изменений дыхательной системы спортсменов І ЭГ и ІІ ЭГ позволили выявить более высокие показатели жизненной емкости легких у представителей экологически условно чистых районов $(4,25 \pm 0,74$ л и 3,91 0,58 л соответственно). Длительность задержки дыхания на вдохе (проба Штанге) у представителей чистых районов оказывается достоверно выше $(p \leq 0,01)$, чем у лиц из загрязненных районов $(76,14 \pm 3,74$ с и $60,10 \pm 2,52$ с соответственно). Проба Штанге оказывает на организм сложное физиологическое воздействие и по механизму является многокомпонентной. Длительность максимальной произвольной задержки дыхания определяется кислородтранспортными функциями организма, чувстви- тельностью инспираторных нейронов к гипоксии и гиперкапнии. Достоверных различий в длительности задержки дыхания на выдохе между представителями различных экологических групп не выявлено, хотя и в данном показателе результат оказывается лучше у представителей условно чистых районов $(40,41 \pm 3,25$ с и $33,92 \pm 3,28$ с соответственно).

Важные структурные изменения, формирующиеся в процессе длительной адаптации к физическим нагрузкам, образуют структурный «след» достаточно сложной архитектуры, который создает возможность интенсивной и в то же время экономичной мышечной работы, составляет базис устойчивой адаптации организма к мышечной работе и условиям внешней среды. Современные антропогенные факторы, представляя огромное разнообразие вредных воздействий на окружающую среду, не имеют направленности своего действия и оказывают неблагоприятное влияние на самого человека.

Результаты исследований сердечно-сосудистой системы спортсменов свидетельствуют о достаточно высокой степени ее адаптированности к физическим нагрузкам у представителей экологически условно чистых районов, что выражается в более низком уровне частоты сердечных сокращений, артериального давления и более высоком уровне ударного объема крови. Это следует рассматривать как предпосылку высокой физической работоспособности и потенциальную способность организма эффективно приспосабливаться к условиям окружающей среды. Показатели центральной гемодинамики спортсменов из загрязненных районов (I ЭГ) в целом соответствуют нормативным показателям, но по сравнению с представителями II ЭГ столь высокой степени адаптированности не отмечается. При анализе результатов исследований индекса адаптационного потенциала системы кровообращения выявлен удовлетворительный уровень ее функционального состояния у обследованных спортсменов, однако, согласно расчету индекса АП сердечно-сосудистая система представителей загрязненных районов находится на грани нормы и напряжения механизмов адаптации. Анализ показателей жизненной емкости легких и длительности задержки дыхания свидетельствует о более высоком уровне адаптации дыхательной системы представителей условно чистых районов по сравнению со спортсменами из загрязненных районов.

Таким образом, результаты проведенных исследований влияния экологических факторов на особенности адаптационных изменений под возжействием занятий физической культурой и спортом, позволяют выявить высокий уровень адаптированности функциональных систем организма и морфологических показателей спортсменов в экологически благополучных районах. 
В районах экологического неблагополучия занятия спортом также формируют структурный след адаптационных изменений, однако его выраженность и уровень проявления оказываются ниже, чем в условно чистых районах. При этом отдельные показатели состояния кардиореспираторной системы спортсменов из загрязненных районов свидетельствуют о напряжении механизмов адаптации.

\section{ЛИТЕРАТУРА}

1. Апокин В.В. Биоритмологический анализ состояния неспецифической адаптоспособности организма спортсменов-пловцов из разных климато-географических регионов / В.В. Апокин [и др.] // Теория и практика физической культуры.— 2014. — № 1.— C. 87-90.

2. Баевский Р.М. Оценка адаптационного потенциала системы кровообращения при массовых профилактических обследованиях / Р.М. Баевский, А.П. Берсенева, Н.Р. Палеев.- М.: ВНИИМИ, 1987.— 19 с.

3. Ванюшин Ю.С. Кардиореспираторная система как индикатор функционального состояния организма спортсменов / Ю.С. Ванюшин, Р.Р. Хайруллин // Теория и практика физической культуры.— 2015.— № 7.- С. 11-14.

4. Годовой доклад об экологической ситуации в Брянской области в 2019 г. Природные ресурсы и окружающая среда Брянской области. / Составители: Г.В. Левкина, О.А. Иванченкова, А.А. Луцевич. // Департамент природных ресурсов и экологии Брянской области.—- Брянск: 000 «Издательство «Читай-город, 2020.- 276 с.

5. Емельянов Б.А. Экология спорта как раздел спортивной науки. Механизм развития эндоэкологических патогенных факторов при спортивной деятельности / Б.А. Емельянов, Л.А. Калинкин, В.А. Левандо // Вестник спортивной науки. — 2011. — № 2. - С. 50-54.

6. Зайцева Н.В. Научные принципы применения биомаркеров в медико-экологических исследованиях (обзор литературы) / Н.В. Зайцева, М.А. Землянова, В.П. Чащин, А.Б. Гудков // Экология человека. — 2019. — № 9.— С. 4-14.

7. Золотникова Г.П. Адаптационный потенциал организма лиц подросткового и юношеского возраста при спортивных нагрузках в современных экологических условиях. Монография / Г.П. Золотникова, Н.Е. Захаров. — Брянск: Изд-во «Белобережье», 2018 г. — 156 с.

( ) Захаров Никита Евгеньевич ( zaxarov1602@yandex.ru ), Шлапакова Светлана Николаевна ( shla-svetlana@yandex.ru ), Кондрашова Ирина Николаевна ( еco-kondrashova@yandex.ru ),Кондыкова Наталия Николаевна ( nkondykova@yandex.ru).

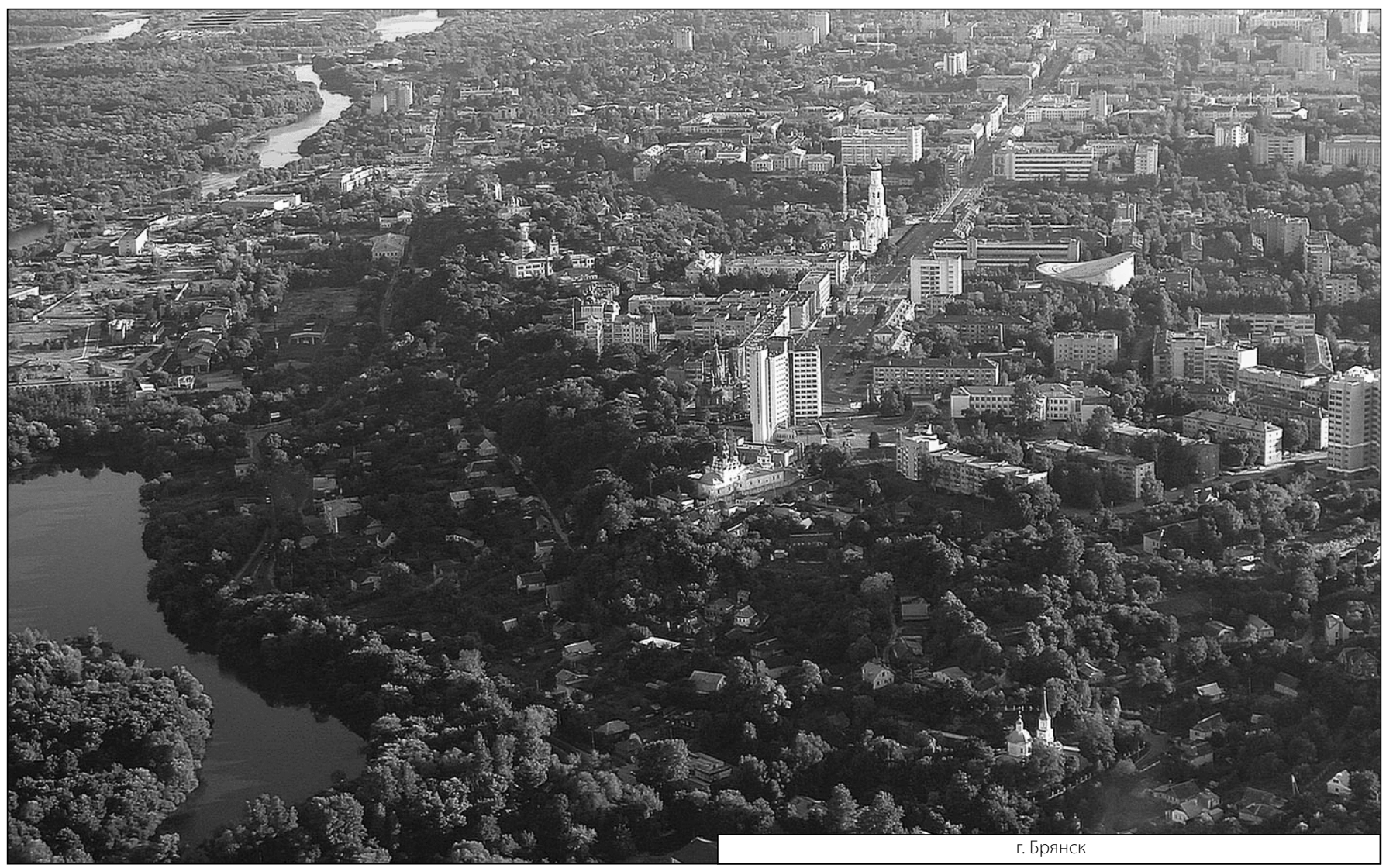

